\title{
STINGRAY: system for integrated genomic resources and analysis
}

\author{
Glauber Wagner ${ }^{1,2,3}$, Rodrigo Jardim, ${ }^{1,4}$, Diogo A Tschoeke ${ }^{1,4}$, Daniel R Loureiro ${ }^{1,4}$, Kary ACS Ocaña ${ }^{1,4}$, \\ Antonio CB Ribeiro ${ }^{1,4,5}$, Vanessa E Emmel ${ }^{1,6}$, Christian M Probst ${ }^{4,7}$, André N Pitaluga ${ }^{5}$, Edmundo C Grisard², \\ Maria C Cavalcanti ${ }^{8}$, Maria LM Campos ${ }^{9}$, Marta Mattoso ${ }^{10}$ and Alberto MR Dávila ${ }^{1,4^{*}}$
}

\begin{abstract}
Background: The STINGRAY system has been conceived to ease the tasks of integrating, analyzing, annotating and presenting genomic and expression data from Sanger and Next Generation Sequencing (NGS) platforms.

Findings: STINGRAY includes: (a) a complete and integrated workflow (more than 20 bioinformatics tools) ranging from functional annotation to phylogeny; (b) a MySQL database schema, suitable for data integration and user access control; and (c) a user-friendly graphical web-based interface that makes the system intuitive, facilitating the tasks of data analysis and annotation.

Conclusion: STINGRAY showed to be an easy to use and complete system for analyzing sequencing data. While both Sanger and NGS platforms are supported, the system could be faster using Sanger data, since the large NGS datasets could potentially slow down the MySQL database usage. STINGRAY is available at http://stingray.biowebdb. org and the open source code at http://sourceforge.net/projects/stingray-biowebdb/.
\end{abstract}

Keywords: Genome, Annotation, Workflow, Next generation sequencing, Sanger, Data integration

\section{Findings}

With the expansion of genomic, transcriptomic and proteomic data, the availability for both intra and inter-specific analyses of nucleotide and protein sequences has raised new levels of difficulty for scientists to understand, integrate and compare this ever increasing information. An important and long lasting problem is how to process and deal with large complex sequence files with distinct formats and using different tools that do not easily exchange data with each other. Thus, researchers must deal with dozens of sequence formats and a variety software packages to analyze nucleotide or protein sequences.

In order to ease such tasks, researchers have been using alternative strategies such as the development of custom ad-hoc scripts, sometimes even ignoring pre-existing

\footnotetext{
* Correspondence: davila@fiocruz.br

'Laboratório de Biologia Computacional e Sistemas, Instituto Oswaldo Cruz (IOC), Fundação Oswaldo Cruz (FIOCRUZ), Avenida Brasil 4365, 21040-360 Rio de Janeiro, Rio de Janeiro, Brazil

${ }^{4}$ Pólo de Biologia Computacional e Sistemas, Instituto Oswaldo Cruz (IOC), Fundação Oswaldo Cruz (FIOCRUZ), Avenida Brasil 4365, 21040-360 Rio de Janeiro, Rio de Janeiro, Brazil

Full list of author information is available at the end of the article
}

generic modules (e.g. Bioperl, Biopython, Bioruby, Biojava). It has been widely used and has proved its efficacy for simple environments, however ad-hoc scripting often results in redundant work and code, difficulties to adapt, which reduces efficiency and is a more error-prone development. Furthermore, the intermediate files generated throughout the process are usually not properly stored and organized, generating a large number of files and versions that can potentially lead to errors in data processing, analyses and/or inferences.

Alongside, the use of database management systems have facilitated several tasks by enforcing integrity constraints, supporting transaction management, concurrent access control, structuring and integrating data into a single schema, and providing structured query languages (SQL), among others.

Another common problem faced by many researchers is the difficulty to handle the installation and working with Unix/Linux-based software, as well as the integration of them. Therefore, the development of user-friendly applications is becoming more common providing a uniform user interface to integrate all these programs with their inputs/ 
outputs in scientific workflows making the annotation and functional analysis process painless to users.

There are several sequence and expression analysis workflows described, such as the EST (Expressed Sequence Tags) pipeline system [1], SABIA [2], GARSA [3], GATO [4], JUICE [5], and others for Next Generation Sequencing (NGS) data analysis, such as NGSPE [6], WEP [7] and DDBJ Pipeline [8]. However, none of these systems were designed to deal at once with EST or GSS (Genome Survey Sequences) data or from different sequencing platform as NGS or Sanger technologies in the same system. Furthermore, those available systems usually don't include protein, phylogenetic and ontology-based analyze such as STINGRAY does. Available workflows usually require some adaptation to optimize performance for each user. For this reason we have designed a flexible workflow in which researchers can use or combine its different sequenced data (subsets of functionalities), according to their needs, in order to ease and turn less time consuming the annotation process, regardless of the size of the genomic dataset.

\section{STINGRAY purpose, development and management}

Considering the previously mentioned challenges, plus the increase of available sequences and multi-teambased projects involving laboratories that are usually geographically dispersed, STINGRAY was conceived as an environment aiming to facilitate the storage, analysis, integration and presentation of genomic and gene expression information. This system integrates several bioinformatics tools and sequence databases, offering a flexible and user-friendly interface.

STINGRAY workflow (Figure 1) was built upon the previous and smaller scale GARSA workflow and sustained significantly improvement as: (a) a larger number of bioinformatics programs; (b) automatic functional prediction and annotation; (c) improvement of phylogenetic analysis; (d) larger and more flexible workflow; (e) the use of a more comprehensive database schema; (f) connection with remote servers for intensive computing; (g) NGS datasets analysis; and (h) a user-friendly configuration interface, resulting in a new and comprehensive system.

The underlying STINGRAY platform includes Perl, Bioperl, CGI, Apache, MySQL, and several Linux-based bioinformatics packages (Table 1). In its current version, the system is able to handle EST, ORESTES and GSS Sanger, as well as NGS (454, SOLiD and Illumina) data, accepting as inputs: (a) Sanger-based chromatograms; (b) NGSbased 454's flowgrams, Illumina's FASTQ and SOLiD's color space; (c) nucleotide or protein FASTA sequences from GenBank [9] (Additional file 1); (d) nucleotide or protein FASTA sequences stored locally; or (e) a combination of all of these inputs. Also, STINGRAY is able to analyze protein sequences, accepting both locally stored or sequences downloaded from GenBank, and to perform comprehensive sequence and genome analysis, distant homology detection and phylogenetic analysis.

The STINGRAY system is being offered as a web server (i.e. CGI-based), so that common users do not need to deal with a large number of dependencies. A web-based setup page is available to configure dependency paths and other features (Additional file 1), thus eliminating the need for interacting directly with the Linux/Unix server. All programs (Table 1) can be configured to run locally (e.g. in the same server where STINGRAY is installed) or remotely, in a different server, like the structure available at Fundação Oswaldo Cruz - FIOCRUZ (Additional file 2).

Nowadays many researchers collaborate in the annotation process in different locations leading to control the different access grants for each user in order to avoid data loss, simultaneous modification, conflicts and security issues. STINGRAY system has data access control for six different user profiles: (a) system administrator; (b) project administrator; (c) "write" users (which can run programs and annotate sequences); (d) "read" users (which are not allowed to run programs or to do annotation); (e) "guest" users (which can only view non-sensitive data and low level of annotation details, and do not have permission to download/upload sequences); and (f) "statistics" users (which can only access statistical data about a project, e.g., total number of sequences analyzed).

\section{STINGRAY workflow}

To provide an integrated view and execution of required tools, the current STINGRAY workflow has two major sections, (I) nucleotide and (II) protein. Both of them share the same initial configuration section (Figure 1). For nucleotide section, STINGRAY workflow uses the Phred [12] package to process chromatograms from Sanger technology, evaluating the traces quality and removing any occasional vector contamination. Following, Repeat Masker [13] is used to find and mask repeated sequences, and CAP3 [14] for clustering the sequences (reads) into a consensus sequence (clusters).

To deal with NGS datasets, MIRA [10] package is used to process 454 flowgrams [29] and Illumina reads, while ABI SOLiD ${ }^{\mathrm{mm}}$ System de novo Accessory Tools 2.0 package and VELVET [11] deal with the color-space dataset. These packages enable STINGRAY to perform the de novo assembly routines, provided by the short-read assemblers generating contigs data set and the output data can be loaded in STINGRAY databases that will consider the each sequence as cluster.

Gene predictions for prokaryote and eukaryote genomes are performed using Glimmer [15] and GlimmerHMM [16], respectively. Furthermore, users can continue with subsequently analysis using (a) all clustered sequences, (b) the Open Reading Frames (ORFs) sequences predicted by gene finders or (c) both. 


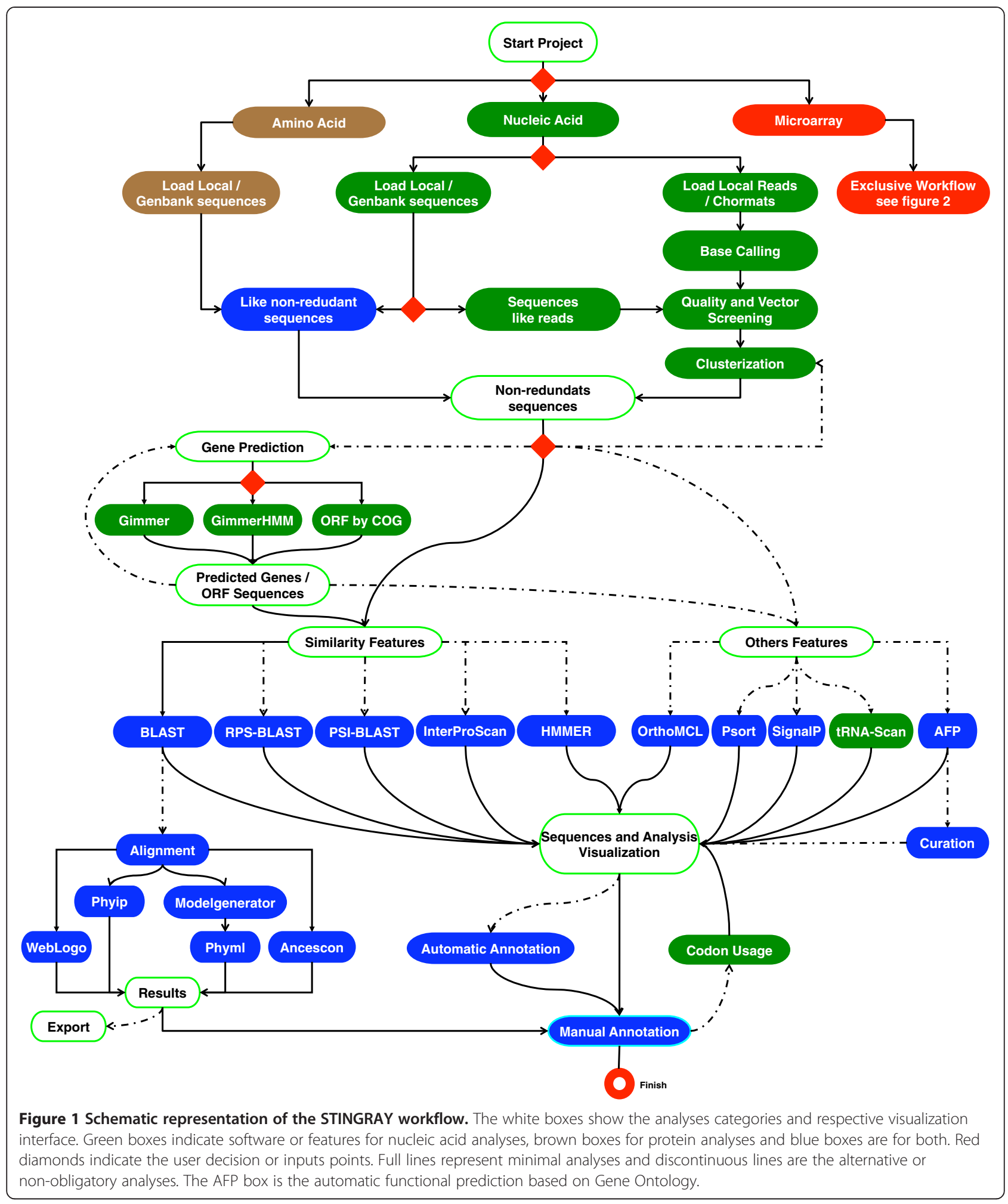

To estimate $\mathrm{G}+\mathrm{C}$ content and codon usage, STINGRAY uses the EMBOSS Geecee and Cusp packages [17], respectively. Clusters or ORFs are then submitted to standalone BLAST [19] for similarity searches against user- defined datasets, downloaded and updated by the server administrator, using an intuitive interface.

To use protein section of STINGRAY workflow, users need to upload the amino acid sequences in FASTA format 


\begin{tabular}{lll} 
Table 1 Bioinformatics software or packages & \\
incorporated on STINGRAY workflow & Ref. \\
\hline Software/packages & Workflow function & {$[10]$} \\
\hline MIRA & Assembly & {$[11]$} \\
Velvet & Assembly & {$[12]$} \\
Phred & Reads quality match & {$[12]$} \\
Crossmatch & Vector mask & {$[13]$} \\
RepeatMasker & Repeat sequence mask & {$[14]$} \\
CAP3 & Sequences clusterization & {$[15]$} \\
Glimmer3 & Prokaryotic gene prediction & {$[16]$} \\
GlimmerHMM & Eukaryotic gene prediction & {$[17]$} \\
Geecee & G+C content calculation & {$[17]$} \\
Cusp & Codon usage calculation & {$[18]$} \\
tRNA-scan & tRNA search & {$[19]$} \\
BLAST & Similarity search & {$[19]$} \\
Rps-BLAST & Conserved domain search & {$[19]$} \\
Psi-BLAST & Similarity search & {$[20]$} \\
Signalp & Signal peptide cleavage sites prediction & {$[21]$} \\
Wolf-Psort & Protein localization & {$[26]$} \\
MAFFT & Multiple sequence alignment construction & {$[22]$} \\
ProbCons & Multiple sequence alignment construction & {$[23]$} \\
WebLogo & Alignment logos generation & {$[24]$} \\
Ancescon & Ancestor sequence prediction & {$[28]$} \\
Phylip & Phylogenetic tree construction \\
Weighbor & Phylogenetic tree construction & \\
ModelGenerator & Evolutionary model search & {$[26]$} \\
& & \\
& &
\end{tabular}

and the system will consider each entry as a unique sequence. It is important to mention that STINGRAY automatically recognizes the project type (nucleotide or protein).

STINGRAY offers to user a phylogenetic module that all three steps typically necessary for molecular phylogenetic analysis, (1) retrieval/inference of homologous sequences, (2) creation of multiple sequence alignments and, (3) phylogenetic tree construction can be performed in STINGRAY. Besides, the system allows the user to infer phylogenetic trees using either full cluster, ORF or high-scoring segment pairs (HSP) obtained automatically by BLAST, then perform multiple sequence alignments generated using ClustalW [30], MAFFT [22] or ProbCons [23] packages. The resulting alignments can be presented in ClustalW, PHYLIP and/or WebLogo formats. Phylogenetic trees are built using SeqBoot, Dnadist, Protdist, Neighbor and Consense software from PHYLIP package [26], as well as Weighbor [27] or Ancescon [25] algorithms. The generated trees are presented in PHYLIP, NEXUS and NEWICK formats, which are available for users visualization and download (Figure 2).

\section{STINGRAY schema}

STINGRAY uses the MySQL Database Management System (DBMS) to store all data in order to improve the performance, data security and management. A relational schema was specially designed to register and straightforward future reference of all data produced by the workflow execution. The schema is able to register data from projects and their users and also permits to maintain data about project-specific configuration and access restrictions. In addition, the STINGRAY data schema also provides some data provenance. For instance, the Cluster table, in the core of the STINGRAY data schema (Additional file 3), records the cluster sequence under investigation and these are connected to the reads used to assemble it by the provenance registered in the Clusters_Reads table. The clustering/ assembly software execution (e.g. CAP3, MIRA or VELVET) is also registered in the Clustering table.

Furthermore, each BLAST analysis is registered in the "Blast_Search" table, which stores information about the parameters values used for that BLAST analysis, such as the sequence database (e.g. NCBI nr, Swissprot), BLAST algorithm (e.g. blastx, blastn) and all BLAST similarity feature, as hit sequences, accessions, score, e-value, consensus sequences, identity and positive values among others are sorted in the Blast_Hit table. So it is possible to link the results with a specific BLAST analysis. The Additional file 4 shows the complete relational schema.

\section{Functional annotation}

Once assembled, sequence clusters are generated and used for subsequent analyses. All sequences and their analyses results can be viewed by a intuitive Web interface (Additional files 5 and 6), such as the Cluster View page where all data analyses for a chosen cluster are summarized (Additional file 7). Users can also compare sequences from a specific library, compare common sequences among all libraries or even obtain libraryspecific sequences. BLAST [19], InterProScan [31], PSIBLAST [19], HMMER [31], tRNA-Scan [18], WolfPsort [21], SignalP [20], Gene Prediction and Automatic Function Prediction (AFP) (by using Glimmer [15] or GlimmerHMM [16]) results are presented in specific tables in a unique interface that holds all necessary information for user analysis (Additional file 8). Besides that, in this interface, the user select sequences to perform phylogenetic analysis as described before (Figure 2). Another important feature provided by STINGRAY is to allow ontology-based functional annotation using Gene Ontology (GO) terms (http://www.geneontology.org/) as part of AFP. This feature was implemented based on similarity results with databases like Seqdblite (GO), UniProtKB (Swiss-Prot and TrEMBL) [32], and InterPro [33] results. Briefly, the GO descriptions, associated to sequences from each quoted databases, are used for 


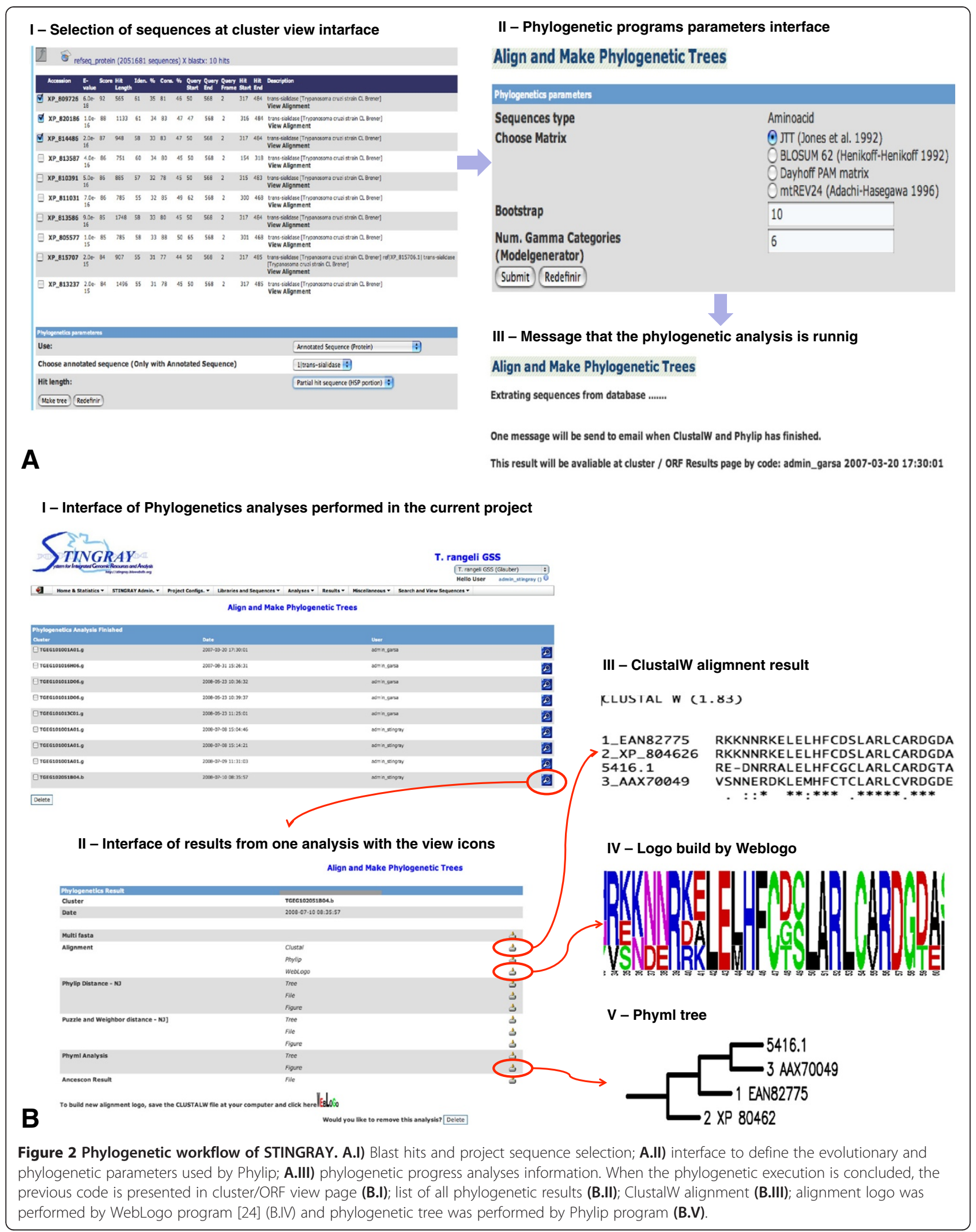


Table 2 Pre-assembly and automatic functional prediction test

\begin{tabular}{|c|c|c|c|c|c|c|c|c|c|c|}
\hline \multirow[t]{2}{*}{ Organism } & \multirow[t]{2}{*}{ Genome size } & \multirow[t]{2}{*}{ SRA $^{1}$} & \multirow[t]{2}{*}{$\begin{array}{l}\text { Sequencing } \\
\text { technology }\end{array}$} & \multirow[t]{2}{*}{ Total reads } & \multirow[t]{2}{*}{$\begin{array}{c}N^{\circ} \text { of } \\
\text { contigs }\end{array}$} & \multirow[t]{2}{*}{$\begin{array}{c}\text { Time of } \\
\text { pre-assembly }\end{array}$} & \multicolumn{4}{|c|}{$\begin{array}{l}\text { Number of sequences } \\
\text { with one GO-based } \\
\text { annotations at least }\end{array}$} \\
\hline & & & & & & & $\mathrm{MF}^{2}$ & $\mathrm{BP}^{3}$ & $\mathrm{CC}^{4}$ & $W A^{5}$ \\
\hline E. coli K12 & $4,7 \mathrm{Mb}$ & SRR001354 & SOLiD & 25162805 & 11011 & $30 \mathrm{~min}$ & 1593 & 1577 & 1562 & 9328 \\
\hline N. meningitidis & $2 \mathrm{Mb}$ & ERR015596 & Illumina & 5418859 & 4815 & $3 \mathrm{~h} 4 \mathrm{~min}$ & 1055 & 1055 & 995 & 2812 \\
\hline S. pneumoniae GA17457 & $2 \mathrm{Mb}$ & SRR068304 & 454 GS FLX & 252646 & 11317 & $2 \mathrm{~h} 52 \mathrm{~min}$ & 5899 & 5942 & 5393 & 5340 \\
\hline P. papatasi & $\sim 170 \mathrm{Mb}$ & SRR066482 & 454 Titanium & 498629 & 9836 & $5 \mathrm{~h} 18 \mathrm{~min}$ & 554 & 553 & 458 & 9993 \\
\hline
\end{tabular}

1 - SRA: Sequence Read Archive.

2 - MF: Molecular Function.

3 - BF: Biological Process.

4 - CC: Cellular component.

5 - WA: Without annotation.

6 - Pre-assemblies were performed on Intel 8 Core Server $(1860 \mathrm{mHz})$ and $16 \mathrm{~Gb}$ RAM.

semi-automatic annotation of clusters, ORFs or proteins. The methodology that scores the terms through accordance and distance methods was incorporated into STINGRAY [34]. The system suggests which terms are more "related" to the protein sequence being analyzed, allowing the user to define the best functional annotation for a sequence during the manual annotation process.

For manual annotation, the user must inform the region of the cluster that corresponds to a coding sequence (CDS) or select one ORF in the list of the cluster. STINGRAY then estimates the $\mathrm{G}+\mathrm{C}$ content, predicts the amino acid sequence for CDS, sub-cellular location (using Wolf-Psort) and peptide cleavage signals (using SignalP). When available, information about (i) Enzyme Commission Code (Union of Biochemistry and Molecular Biology), (ii) Monica Riley classification, (iii) most similar species, (iv) BLAST similarity, (v) domain, and (vi) notes about sequences, are automatically included as part of the annotation process (Additional file 8). After one sequence has been annotated by AFP, the user can manually verify the results through an interface to confirm or update the automatic annotation.

Since STINGRAY is a multi-user system, the confidentially and maintenance integrity of the data are important. To achieve this level of security only "project administrator" and "write" users can modify and run the programs for sequence annotation. Nevertheless, only project administrators have permission to remove data.

Once a project in STINGRAY is finished/published, the project administrator allows, upon user request, the data and analyses to become public, and then the scientific community (or "read" users) can view some project details (Additional file 9), statistics (Additional file 10) and graphics.

A common concern in sequencing projects, especially EST and GSS projects, is the GenBank submission of the annotated sequences. In order to facilitate and enable the submission, STINGRAY provides an intuitive interface where sequences and data are formatted according to the GenBank requirements. Since the system does not perform automatic submission, the formatted file must be submitted to GenBank by the project administrator per se.

Table 3 Features comparison between Stingray and other annotation pipelines

\begin{tabular}{|c|c|c|c|c|c|}
\hline Features & STINGRAY & RATT & Artemis & WEP & NGSPE \\
\hline $\begin{array}{l}\text { Preproccesing sequencing } \\
\text { output data files }\end{array}$ & $x$ & & & $x$ & $x$ \\
\hline $\begin{array}{l}\text { Proccesing Sanger } \\
\text { output files }\end{array}$ & $x$ & & & & \\
\hline Proccesing NGS output files & $x$ & & & $x$ & $x$ \\
\hline Gene prediction & $x$ & $x$ & $x$ & & \\
\hline Similarity search blast & $x$ & & $x$ & & \\
\hline Similarity search Hmmer & $x$ & & $x$ & & \\
\hline Similarity search RPSBlast & $x$ & & $x$ & & \\
\hline Similarity search Interpro & $x$ & & & & \\
\hline Similarity search PSIBlast & $x$ & & & & \\
\hline Homologs identification & $x$ & $x$ & & & \\
\hline Phylogeny analysis & $x$ & & & & \\
\hline Codon usage analysis & $x$ & & & & \\
\hline tRNA prediction & $x$ & & & & \\
\hline Manual annotation & $x$ & & $x$ & & \\
\hline Semi-automatic annotation & $x$ & & & & \\
\hline Automatic annotation & $x$ & $x$ & & $x$ & $x$ \\
\hline Friendly interface & $x$ & & $x$ & & \\
\hline Web platform & $x$ & & & $x$ & \\
\hline Use of SGBD & $x$ & & & $x$ & \\
\hline Applet & & & $x$ & & \\
\hline $\begin{array}{l}\text { Browse genome } \\
\text { visualization }\end{array}$ & & & $x$ & & \\
\hline Jalview visualization & & & $x$ & & \\
\hline Generate GBFF file & $x$ & & $x$ & & \\
\hline Generate Seqln file & $x$ & & $x$ & & \\
\hline
\end{tabular}


Pre-assembly and automatic functional prediction

In order to test the STINGRAY workflow, bacterial genomes from Escherichia coli K12, Neisseria meningitides, Streptococcus pneumoniae GA17457, and a eukaryotic genome: Phlebotomus papatasi (NCBI Sequence Read Archive number SRX000353, ERX005963, SRX028097 and SRX027131, respectively) were processed, pre-assembled then AFP was performed. The time of pre-assembly, GObased annotations, and numbers of contigs obtained by pre-assembly for each of the four data sets are listed in Table 2.

\section{Conclusions}

Nowadays, STINGRAY is hosting more than 20 different projects, among them the T. vivax (GSS and EST) [35], Bothrops jararaca (EST) [36], Lutzomyia longipalpis (EST) [37,38], Taenia solium (EST) [39] and Trypanosoma rangeli (GSS, EST and ORESTES) [40]. The main advantage of STINGRAY over related systems is its larger and flexible workflow on which advanced users or annotators are able to fine-tune the parameters of some programs to extract the maximum of valuable information and knowledge from their sequences.

The STINGRAY pipeline is able to manipulate both Sanger and NGS sequence data in the same project (Table 3), whereas other (recently developed) pipelines do not longer center on Sanger technology. Since Sanger sequencing is still widely used, a system being able to deal with these two technologies should be seen as an advantage. Assembly quality is strongly dependent on quantity (coverage) and quality of data/reads as well as "fine tuning" of the many parameters available in the genome assembler software, then while the pre-assembly performed was done with the only purpose to illustrate the STINGRAY functionalities, the results obtained showed to be a good starting point for additional and robust assembly process.

Furthermore, STINGRAY offers a complete annotation pipeline, allowing the user to perform automatic, semiautomatic and manual annotation, while others pipelines like RATT [41], WEP [6] and NGSPE [7] perform only automatic annotation. STINGRAY also allows the user to edit annotations being, along Artemis [42,43], the unique systems with such feature. Up to the current version, STINGRAY is the only pipeline which allows the use of Intepro Search, Phylogeny analysis, Codon Usage Analysis and tRNA sequence prediction in a integrated way, then being a web-based platform with friendly interface is a plus.

Due the open-source nature, future developments and improvements such as the incorporation and analysis of DNA-, RNA- or Methyl-sequencing data as well as analysis of sequence, functional or structural variants are possible. Also, the use of "cloud-based" applications as part of the STINGRAY workflow, either using private clouds or even commercial ones as Amazon's (http://aws.amazon. com/ec2/), are being considered. In the current context of larger high-throughput sequence generation, the use of cloud computing is the way forward. Larger and improved database schemas as GUS (Genomics Unified Schema) (http://www.gusdb.org/) could be potentially used to content different datasets and sequence features. Data integration using LOD (Linked Open Data) technology is also planned for the next version, as it is now clear that connecting local data with many other sources (curated, non-curated or even complementary) in the LOD cloud (http://lod-cloud.net/versions/2007-11-10/lod-cloud.png) might help to accelerate knowledge extraction. Online documentation for installation using STINGRAY and technical information are available at http://stingray. biowebdb.org and on Additional File 11.

\section{Availability and requirements}

Project name: STINGRAY (BiowebDB)

Project home page: http://sourceforge.net/projects/stingraybiowebdb/

Operating system(s): Unix

Programming language: Perl

Other requirements: Perl, Apache, MySQL

License: GNU GPLv2.

Any restrictions to use by non-academics: license

\section{Availability of supporting data}

The data set(s) supporting the results of this article is (are) included within the article (and its additional file(s)).

\section{Additional files}

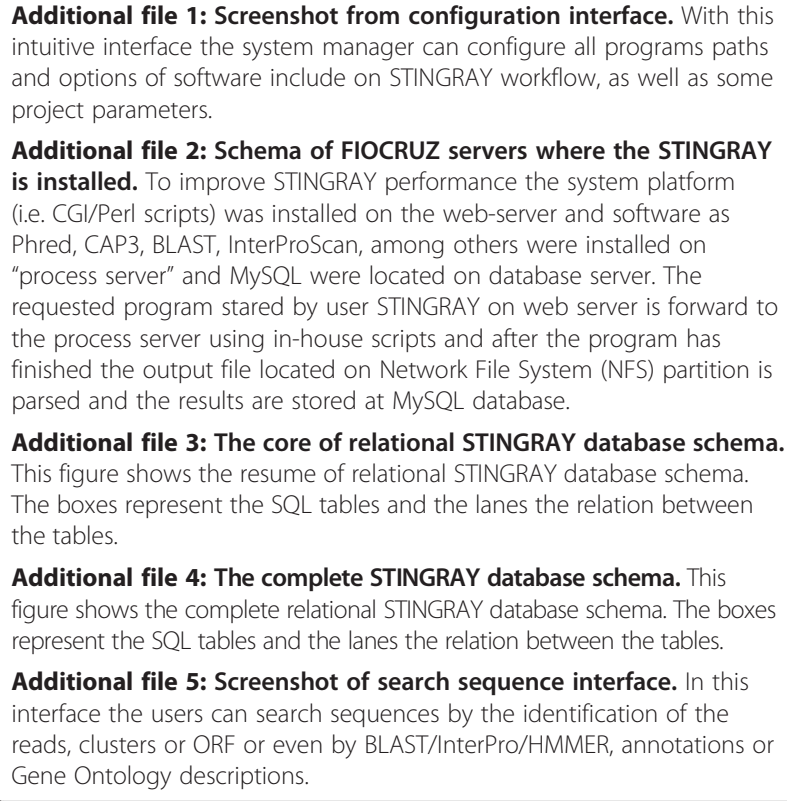

Additional file 1: Screenshot from configuration interface. With this intuitive interface the system manager can configure all programs paths and options of software include on STINGRAY workflow, as well as some project parameters.

Additional file 2: Schema of FIOCRUZ servers where the STINGRAY is installed. To improve STINGRAY performance the system platform (i.e. CGI/Perl scripts) was installed on the web-server and software as Phred, CAP3, BLAST, InterProScan, among others were installed on "process server" and MySQL were located on database server. The requested program stared by user STINGRAY on web server is forward to the process server using in-house scripts and after the program has finished the output file located on Network File System (NFS) partition is parsed and the results are stored at MySQL database.

Additional file 3: The core of relational STINGRAY database schema. This figure shows the resume of relational STINGRAY database schema. The boxes represent the SQL tables and the lanes the relation between the tables.

Additional file 4: The complete STINGRAY database schema. This figure shows the complete relational STINGRAY database schema. The boxes represent the SQL tables and the lanes the relation between the tables.

Additional file 5: Screenshot of search sequence interface. In this interface the users can search sequences by the identification of the reads, clusters or ORF or even by BLAST/InterPro/HMMER, annotations or Gene Ontology descriptions. 
Additional file 6: Screenshot of BLAST results search interface. Using this interface the user can view the all similarity BLAST results. Notice the other results interfaces are available at the upper menu.

Additional file 7: Screenshot of cluster view interface. This intuitive interface shows all cluster features, like length, reads and similarity results obtain by BLAST, InterProScan and HMMER results. The ORF view interface is similar.

Additional file 8: Screenshot of annotation (CDS) interface. This interface allowed user to annotate the sequence and insert other important information.

Additional file 9: Screenshot of a current available project. This is the specific project page, with the information about the project and number of sequences.

Additional file 10: Statistic reports interface screenshot. In this interface the user can view the summary of the current project data.

Additional file 11: STINGRAY source code. All scripts and web pages needed to setup STINGRAY are available in this compressed file.

\section{Abbreviations}

AFP: Automatic function prediction; BLAST: Basic local alignment search tool; CDS: Coding sequences; CGI: Common gateway interface; DBMS: Database management system; DDBJ: DNA Data Bank of Japan; EMBOSS: The European Molecular Biology Open Software Suite; EST: Expressed sequence tags; GARSA: Genomic analysis resources for sequence annotation; GATO: Gene annotation tool; GSS: Genomic sequence survey; GO: Gene Ontology; GUS: Genomics unified schema; LOD: Linked open data; MPI: Message passing interface; NCBI: National Center for Biotechnology Information; NFS: Network file system; NGS: Next generation sequencing; ORESTES: Open reading frame ESTs; ORF: Open reading frames; PERL: Practical extraction and report language; PSI-BLAST: Reversed position specific BLAST; RPS-BLAST: Position specific iterative BLAST; SABIA: System for annotation bacterial (genome) integrated annotation; SQL: Structured query language; STINGRAY: System for integrated genomic resources and analysis; tRNA: Ribonucleic acid transporter.

\section{Competing interests}

All other authors declare that they have no competing interests.

\section{Authors' contributions}

GW, DAT and DRL were responsible for programming, development and tests with Sanger data. KACSO participated in the programming and development of some bioinformatics tasks and drafted the manuscript. RJ, ACBR and VEE participated in the assembly development and tested the system. CMP, ANP, ECG, MCC, MLMC, MM, AMRD conceived of the study, and participated in its design and coordination and helped to draft the manuscript. All authors read and approved the final manuscript.

\section{Acknowledgements}

To Brazilian sponsors CNPq, FAPERJ and CAPES for financial support. To Pablo Mendes, Sérgio Serra, Milene Guimarães, Raphael Tavares, Guilherme Geronimo, Michel Abanto and Ana CP Vicente for useful discussions and help either during the early stage of development or the final testing of the system.

\section{Author details}

'Laboratório de Biologia Computacional e Sistemas, Instituto Oswaldo Cruz (IOC), Fundação Oswaldo Cruz (FIOCRUZ), Avenida Brasil 4365, 21040-360 Rio de Janeiro, Rio de Janeiro, Brazil. ${ }^{2}$ Laboratório de Protozoologia, Departamento de Microbiologia, Imunologia e Parasitologia (MIP), Centro de Ciências Biológicas (CCB), Universidade Federal de Santa Catarina (UFSC), Campus Universitário, Setor F, Bloco A, Trindade, 88040-970, Caixa Postal 476, Florianópolis, Santa Catarina, Brazil. ${ }^{3}$ Laboratório de Doenças Infecciosas e Parasitárias (LDIP), Área de Ciências Biológicas e da Saúde (ACBS),

Universidade do Oeste de Santa Catarina (Unoesc), Rua Getúlio Vargas 2125, Flor da Serra, 89600-000 Joaçaba, Santa Catarina, Brazil. ${ }^{4}$ Pólo de Biologia Computacional e Sistemas, Instituto Oswaldo Cruz (IOC), Fundação Oswaldo Cruz (FIOCRUZ), Avenida Brasil 4365, 21040-360 Rio de Janeiro, Rio de Janeiro, Brazil. ${ }^{5}$ Laboratório de Biologia Molecular de Parasitas e Vetores, Instituto Oswaldo Cruz (IOC), Fundação Oswaldo Cruz (FIOCRUZ), Avenida Brasil 4365, 21040-360 Rio de Janeiro, Rio de Janeiro, Brazil. '́Laboratório de
Genética Molecular de Microrganismos, Instituto Oswaldo Cruz (IOC), Fundação Oswaldo Cruz (FIOCRUZ), Avenida Brasil 4365, 21040-360 Rio de Janeiro, Rio de Janeiro, Brazil. 'aboratório de Bioinformática, Instituto Carlos Chagas (ICC), Fundação Oswaldo Cruz (FIOCRUZ), Avenida Algacyr Munhoz Mader, 3775, Cidade Industrial, 81350-010 Curitiba, Paraná, Brazil. ${ }^{8}$ Instituto Militar de Engenharia (IME), Seção de Engenharia de Computação (SE-8), Praça General Tibúrcio 80, Praia Vermelha, Urca, 22290-270 Rio de Janeiro, Rio de Janeiro, Brazil. ${ }^{9}$ Instituto de Matemática, Departamento de Ciência da Computação, Universidade Federal do Rio de Janeiro, Bloco C, CCMN, Sala E-2206, llha do Fundão, 21945-970 Rio de Janeiro, Rio de Janeiro, Brazil. ${ }^{10}$ Instituto Alberto Luiz Coimbra de Pós-graduação e Pesquisa de Engenharia (COPPE), Universidade Federal do Rio de Janeiro, P.O. Box 68511, Itha do Fundão, 21941-972 Rio de Janeiro, Rio de Janeiro, Brazil.

Received: 16 October 2013 Accepted: 28 February 2014 Published: 7 March 2014

\section{References}

1. Xu H, He L, Zhu Y, Huang W, Fang L, Tao L, Zhu Y, Cai L, Xu H, Zhang L, Xu H, Zhou Y: EST pipeline system: detailed and automated EST data processing and mining. Genomics Proteomics Bioinformatics 2003, 1:236-242.

2. Almeida LGP, Paixão R, Souza RC, da Costa GC, Barrientos FJA, dos Santos MT, de Almeida DF, Vasconcelos ATR: A System for Automated Bacterial (genome) Integrated Annotation-SABIA. Bioinformatics 2004, 20:2832-2833.

3. Dávila AMR, Lorenzini DM, Mendes PN, Satake TS, Sousa GR, Campos LM, Mazzoni CJ, Wagner G, Pires PF, Grisard EC, Cavalcanti MCR, Campos MLM: GARSA: genomic analysis resources for sequence annotation. Bioinformatics 2005, 21:4302-4303.

4. Fujita A, Massirer KB, Durham AM, Ferreira CE, Sogayar MC: The GATO gene annotation tool for research laboratories. Braz J Med Biol Res 2005, 38:1571-1574

5. Latorre M, Silva H, Saba J, Guziolowski C, Vizoso P, Martinez V, Maldonado J, Morales A, Caroca R, Cambiazo V, Campos-Vargas R, Gonzalez M, Orellana A, Retamales J, Meisel LA: JUICE: a data management system that facilitates the analysis of large volumes of information in an EST project workflow. BMC Bioinforma 2006, 7:513.

6. Huang K, Yellapantula V, Baier L, Dinu V: NGSPE: a pipeline for end-to-end analysis of DNA sequencing data and comparison between different platforms. Comput Biol Med 2013, 43:1171-1176.

7. D'Antonio M, D'Onorio De Meo P, Paoletti D, Elmi B, Pallocca M, Sanna N, Picardi E, Pesole G, Castrignanò T: WEP: a high-performance analysis pipeline for whole-exome data. BMC Bioinforma 2013, 14(Suppl 7):S11.

8. Nagasaki H, Mochizuki T, Kodama Y, Saruhashi S, Morizaki S, Sugawara H, Ohyanagi H, Kurata N, Okubo K, Takagi T, Kaminuma E, Nakamura Y: DDBJ read annotation pipeline: a cloud computing-based pipeline for highthroughput analysis of next-generation sequencing data. DNA Res 2013, 20:383-390

9. Benson DA, Karsch-Mizrachi I, Clark K, Lipman DJ, Ostell J, Sayers EW: GenBank. Nucleic Acids Res 2012, 40:D48-D53.

10. Chevreux B, Pfisterer T, Drescher B, Driesel AJ, Müller WEG, Wetter T, Suhai S: Using the miraEST assembler for reliable and automated mRNA transcript assembly and SNP detection in sequenced ESTs. Genome Res 2004, 14:1147-1159.

11. Zerbino DR, Birney E: Velvet: algorithms for de novo short read assembly using de Bruijn graphs. Genome Res 2008, 18:821-829.

12. Machado M, Magalhães WC, Sene A, Araújo B, Faria-Campos AC, Chanock SJ, Scott L, Oliveira G, Tarazona-Santos E, Rodrigues MR: Phred-Phrap package to analyses tools: a pipeline to facilitate population genetics re-sequencing studies. Investig Genet 2011, 2:3.

13. Smit AFA, Hubley R, Green P: RepeatMasker. [http://www.repeatmasker.org]

14. Huang X, Madan A: CAP3: a DNA sequence assembly program. Genome Res 1999, 9:868-877.

15. Delcher AL, Bratke KA, Powers EC, Salzberg SL: Identifying bacterial genes and endosymbiont DNA with glimmer. Bioinformatics 2007, 23:673-679.

16. Majoros WH, Pertea M, Salzberg SL: TigrScan and GlimmerHMM: two open source ab initio eukaryotic gene-finders. Bioinformatics 2004, 20:2878-2879.

17. Rice P, Longden I, Bleasby A: EMBOSS: the European molecular biology open software suite. Trends Genet 2000, 16:276-277.

18. Lowe TM, Eddy SR: tRNAscan-SE: a program for improved detection of transfer RNA genes in genomic sequence. Nucleic Acids Res 1997, 25:955-964. 
19. Altschul SF, Madden TL, Schäffer AA, Zhang J, Zhang Z, Miller W, Lipman DJ: Gapped BLAST and PSI-BLAST: a new generation of protein database search programs. Nucleic Acids Res 1997, 25:3389-3402.

20. Petersen TN, Brunak S, von Heijne G, Nielsen H: SignalP 4.0: discriminating signal peptides from transmembrane regions. Nat Methods 2011, 8:785-786.

21. Horton P, Park K-J, Obayashi T, Fujita N, Harada H, Adams-Collier CJ, Nakai K. WoLF PSORT: protein localization predictor. Nucleic Acids Res 2007 35:W585-W587.

22. Katoh K, Toh H: Parallelization of the MAFFT multiple sequence alignment program. Bioinformatics 2010, 26:1899-1900.

23. Do CB, Mahabhashyam MSP, Brudno M, Batzoglou S: ProbCons: probabilistic consistency-based multiple sequence alignment. Genome Res 2005, 15:330-340.

24. Crooks GE, Hon G, Chandonia J-M, Brenner SE: WebLogo: a sequence logo generator. Genome Res 2004, 14:1188-1190.

25. Cai W, Pei J, Grishin NV: Reconstruction of ancestral protein sequences and its applications. BMC Evol Biol 2004, 4:33.

26. Felsenstein J: PHYLIP - phylogeny inference package (version 3.2). Cladistics 1989, 5:164-166.

27. Bruno WJ, Socci ND, Halpern AL: Weighted neighbor joining: a likelihoodbased approach to distance-based phylogeny reconstruction. Mol Biol Evol 2000, 17:189-197.

28. Keane TM, Creevey CJ, Pentony MM, Naughton TJ, McInerney JO: Assessment of methods for amino acid matrix selection and their use on empirical data shows that ad hoc assumptions for choice of matrix are not justified. BMC Evol Biol 2006, 6:29.

29. Margulies M, Egholm M, Altman WE, Attiya S, Bader JS, Bemben LA, Berka J, Braverman MS, Chen Y-J, Chen Z, Dewell SB, Du L, Fierro JM, Gomes XV, Godwin BC, He W, Helgesen S, Ho CH, Ho CH, Irzyk GP, Jando SC, Alenquer MLI, Jarvie TP, Jirage KB, Kim J-B, Knight JR, Lanza JR, Leamon JH, Lefkowitz SM, Lei $M$, et al: Genome sequencing in microfabricated high-density picolitre reactors. Nature 2005, 437:376-380.

30. Larkin MA, Blackshields G, Brown NP, Chenna R, McGettigan PA, McWilliam $H$, Valentin F, Wallace IM, Wilm A, Lopez R, Thompson JD, Gibson TJ, Higgins DG: Clustal W and Clustal X version 2.0. Bioinformatics 2007, 23:2947-2948

31. Zdobnov EM, Apweiler R: InterProScan-an integration platform for the signature-recognition methods in InterPro. Bioinformatics 2001, 17:847-848.

32. Apweiler R: UniProt: the universal protein knowledgebase. Nucleic Acids Res 2004, 32:115D-119D.

33. Hunter $S$, Jones $P$, Mitchell A, Apweiler R, Attwood TK, Bateman A, Bernard T, Binns D, Bork P, Burge $S$, de Castro E, Coggill P, Corbett M, Das U, Daugherty L, Duquenne L, Finn RD, Fraser M, Gough J, Haft D, Hulo N, Kahn D, Kelly E, Letunic I, Lonsdale D, Lopez R, Madera M, Maslen J, McAnulla C, McDowall J, et al: InterPro in 2011: new developments in the family and domain prediction database. Nucleic Acids Res 2011, 40:D306-D312.

34. Jones CE, Baumann U, Brown AL: Automated methods of predicting the function of biological sequences using GO and BLAST. BMC Bioinforma 2005, 6:27.

35. Guerreiro LT, Souza SS, Wagner G, De Souza EA, Mendes PN, Campos LM, Barros L, Pires PF, Campos ML, Grisard EC, Dávila AM: Exploring the genome of Trypanosoma vivax through GSS and in silico comparative analysis. OMICS 2005, 9:116-128.

36. Cidade DA, Simão TA, Dávila AM, Wagner G, Junqueira-de-Azevedo IL, Ho PL Bon C, Zingali RB, Albano RM: Bothrops jararaca venom gland transcriptome: analysis of the gene expression pattern. Toxicon 2006, 48:437-461.

37. Pitaluga AN, Beteille V, Lobo AR, Ortigão-Farias JR, Dávila AM, Souza AA, Ramalho-Ortigão JM, Traub-Cseko YM: EST sequencing of blood-fed and Leishmania-infected midgut of Lutzomyia longipalpis, the principal visceral leishmaniasis vector in the Americas. Mol Genet Genomics 2009, 282:307-317.

38. Azevedo RV, Dias DB, Bretãs JA, Mazzoni CJ, Souza NA, Albano RM, Wagner G, Davila AM, Peixoto AA: The transcriptome of Lutzomyia longipalpis (Diptera: Psychodidae) male reproductive organs. PLoS One 2012, 7:e34495.

39. Almeida CR, Stoco PH, Wagner G, Sincero TC, Rotava G, Bayer-Santos E, Rodrigues JB, Sperandio MM, Maia AA, Ojopi EP, Zaha A, Ferreira HB, Tyler KM, Dávila AM, Grisard EC, Dias-Neto E: Transcriptome analysis of taenia solium cysticerci using open reading frame ESTs (ORESTES). Parasit Vectors 2009, 2:35.
40. Grisard EC, Stoco PH, Wagner G, Sincero TC, Rotava G, Rodrigues JB, Snoeijer CQ Koerich LB, Sperandio MM, Bayer-Santos E, Fragoso SP, Goldenberg S, Triana O, Vallejo GA, Tyler KM, Dávila AM, Steindel M: Transcriptomic analyses of the avirulent protozoan parasite Trypanosoma rangeli. Mol Biochem Parasito/ 2010, 174:18-25

41. Otto TD, Dillon GP, Degrave WS, Berriman M: RATT: rapid annotation transfer tool. Nucleic Acids Res 2011, 39:e57.

42. Rutherford K, Parkhill J, Crook J, Horsnell T, Rice P, Rajandream MA, Barrell B: Artemis: sequence visualization and annotation. Bioinformatics 2000, 16:944-945.

43. Carver T, Harris SR, Berriman M, Parkhill J, McQuillan JA: Artemis: an integrated platform for visualization and analysis of high-throughput sequence-based experimental data. Bioinformatics 2012, 28:464-469.

doi:10.1186/1756-0500-7-132

Cite this article as: Wagner et al: STINGRAY: system for integrated genomic resources and analysis. BMC Research Notes 2014 7:132.

\section{Submit your next manuscript to BioMed Central and take full advantage of:}

- Convenient online submission

- Thorough peer review

- No space constraints or color figure charges

- Immediate publication on acceptance

- Inclusion in PubMed, CAS, Scopus and Google Scholar

- Research which is freely available for redistribution

Submit your manuscript at www.biomedcentral.com/submit
C BioMed Central 